\title{
Prostat kanseri kemik metastazları
}

\section{Prostate cancer metastases}

\author{
Mehmet Yalçınozan ${ }^{1}$, Osman Rodop ${ }^{2}$, Kaan Erler ${ }^{1}$ \\ 'Yakın Doğu Üniversitesi Hastanesi, Ortopedi ve Travmatoloji Anabilim Dalı, Lefkoşa, KKTC \\ ${ }^{2}$ Istinye Üniversitesi Tıp Fakültesi, Ortopedi ve Travmatoloji Anabilim Dalı, İstanbuL
}

Prostat kanserleri, erkeklerde en sık tanı alan ve en çok ölüme neden olan ilk beş kanser tipi arasındadır. Prostat kanserlerinin $\% 95$ 'i, prostatik bez veya kanal asinisinden kaynaklanan adenokarsinomalardır. Erken tanı ve tedavi yöntemlerinin etkin olmasıyla birlikte yaşam beklentisinin artışı, prostat kanserlerinde metastaz oranlarının yüksekliğini açıklamaktadır. Tedaviye dirençli metastatik prostat kanserlerinde kemik metastazlarına ait radyolojik bulguların yaklaşık \%90 oranında mevcut ve hastaların \%80'inde ilk metastaz alanının kemik olduğu belirtilmektedir. Prostat kanserlerinin kemiğe en sık metastaz yaptığı yerler arasında kostalar, vertebra ve pelvis olmakla beraber kraniyum ve uzun kemiklerde de metastazlar literatürde bildirilmiştir. Günümüzde alt üriner sistem semptomları (AÜSS) olarak adlandırılan prostatizm belirtileri, prostat kanserinin başlıca semptomları arasında sayılabilir. Hastaların çekilen direkt grafilerinde sıklıkla osteoblastik aktivite artışına bağlı yaygın sklerotik odaklar saptanmaktadır. Aynı şekilde, grafilerde litik lezyonlara da rastlanabilmektedir. Prostat kanseri evrelemesinde klasik olarak TNM (tümör, lenf nodu, metastaz) sınıflaması kullanılır. Prostat kanserinde klinik evrelemenin amacı, hastalığın yaygınlığını kestirmek ve hastalığın tahmini prognozuna göre en uygun tedavi algoritmasını oluşturmaktır. Buna göre, düşük riskli gruplarda evreleme amaçı ileri radyolojik tetkik yapılması önerilmez. Orta risk grubundaki hastalarda ve yüksek risk grubu hastalarda ise kemik sintigrafisi, bilgisayarlı tomografi (BT) veya manyetik rezonans (MR) inceleme yapılması önerilir. Tanı alan hastalarda risk gruplarına göre, tedavide uygulanabilecek yöntemler: aktif izlem, semptomatik tedavi, radikal prostatektomi, radyoterapi ve brakiterapi olarak sayılabilir.

Anahtar sözcülkler: prostat; kanser; kemik; metastaz
Prostate cancers are among the top five types of cancers that are most commonly diagnosed and mostly cause death in men. $95 \%$ of prostate cancers are adenocarcinomas originating from prostatic gland acinis. The increase in life expectancy with early diagnosis and treatment methods explains the high rate of metastasis in prostate cancer. It is reported that $90 \%$ of the radiological findings of bone metastases are present in treatment-resistant metastatic prostate cancers, and the first metastasis site in $80 \%$ of these patients is the bone. The prostate cancers that most commonly metastasize to bone include ribs, vertebrae, and pelvis; but metastases in cranium and long bones have also been reported in the literature. The symptoms of prostatism, now called lower urinary tract symptoms (LUTS), are among the main symptoms of prostate cancer. X-ray radiographs of the patients usually show widespread sclerotic foci due to increased osteoblastic activity. Likewise, lytic lesions can be seen on radiographs. Classically, TNM (tumor, lymph node, metastasis) classification is utilized in prostate cancer staging. The aim of clinical staging in prostate cancer is to estimate the prevalence of the disease, and to establish the most appropriate treatment algorithm according to the prognosis. Accordingly, advanced staging for low-risk groups is not recommended. Bone scintigraphy, computed tomography $(C T)$ or magnetic resonance imaging (MRI) are recommended for the middle-risk and high-risk patients. Active monitoring, symptomatic treatment, radical prostatectomy, radiotherapy, and brachytherapy are the treatment modalities according to the risk groups.

Key words: prostate; cancer; bone; metastasis insiyet spesifik organ olması nedeniyle sadece erkeklerde görülen prostat kanserleri, erkeklerde en sık tanı alan ikinci, en sık ölüme neden olan beşinci kanser tipi olarak bilinmektedir. 2012 yılı verilerine göre, dünya çapında yıllık \%15 (1,1 milyon) yeni tanı konmuş olgu ve \%7 (307.000) kansere bağlı ölüm sayısı açıklanmıştır. ${ }^{[1]}$ Muayeneye ek olarak, prostata özgü antijen (PSA) kanserin tanı ve tedavi takibinde önemli rol oynar. Duyarlılığının yüksek fakat özgüllüğünün düşük oluşu hastalığın erken tanı almasına yardımcı olmakla beraber, yanlış tanı alan hastalara bağlı olarak, kansere bağlı ölüm oranlarının tespiti

- Illetişim adresi: Yard. Doç. Dr. Mehmet Yalçınozan, Yakın Doğu Üniversitesi Hastanesi, Ortopedi ve Travmatoloji Anabilim Dalı, 91380 Lefkoşa, KKTC, Mersin 10, Türkiye Tel: 0533 - 8835791 e-posta: mehmet.yalcinozan@med.neu.edu.tr

- Geliș tarihi: 13 Eylül $2019 \quad$ Kabul tarihi: 22 Ekim 2019 
zorlaşmaktadır. ${ }^{[2]}$ Tanı ve evrelemede, başta ultrasonografi (US) olmak üzere, diğer radyolojik yöntemlerden de yararlanılan prostat kanserlerinde, kesin tanı sonrası androjen bağımlı prostat kanserlerinin tedavisi medikal veya cerrahi kastrasyon ile düzenlenir. Erken tanıyla beraber, oldukça etkili olan medikal tedavide kullanılan androjen baskılayıcı ajanların, istenilen kan testosteron seviyelerine ulaştıktan sonra sürekli olarak kullanııması önerilir. Buna rağmen, birçok olguda hastalık düşük testosteron seviyelerine rağmen ilerleyici olabilir $^{[3]}$ ve hastalarda ileri dönemde metastatik kanserler oluşabilir.

\section{Fizyopatoloji}

Prostat kanserlerinin \%95'i prostatik bez veya kanal asinisinden kaynaklanan adenokarsinomalardır. ${ }^{[4]}$ Erken tanı ve tedavi yöntemlerinin etkin olmasıyla yaşam beklentisinin artışı, prostat kanserlerinde metastaz oranlarının yüksekliğini açıklamaktadır. ${ }^{[5]}$ Prostat kanseri, lokal invazyon (örn.; mesane ve seminal veziküller), lenfatik (sırasıyla pelvik, paraaortik ve inguinal) veya hematojenik yolla metastaz yapabilir. ${ }^{[6]}$ Prostat kanserinin kemik metastazı yapmaya meyilli olduğu bilinmekle beraber, hematojenik yolla metastaz yaptığı başlıca dokular şunlardır: ${ }^{[7]}$

- Kemik (\%90)

- Akciğer (\%45)

- Karaciğer (\%25)

- Plevra (\%20)

- Adrenal bezler (\%15)

Kırk yaş üzerinde prostat kanseri tanılı 1589 hastanın yapılan otopsileriyle ilgili bir analizde, \%35 hastada metastaz bulguları olmakla beraber, bunların \%90'ının kemik metastazı olduğu raporlanmıştır. ${ }^{[7]}$ Başka yayınlarda ise, tedaviye dirençli metastatik prostat kanserlerinde kemik metastazlarına ait radyolojik bulguların yaklaşık \%90 oranında mevcut ve hastaların \%80'inde ilk metastaz alanının kemik olduğu belirtilmektedir. [5] Prostat kanserlerinin kemiğe en sık metastaz yaptığ yerler arasında kostalar, vertebra ve pelvis olmakla beraber, kraniyum ve uzun kemiklerde de metastazlar literatürde bildirilmiştir. ${ }^{[8]}$

Prostat kanseri kemik metastazlarının osteoblastik aktivitesi, radyografide yeni kemik oluşumu (Şekil 1), kemik taramasında artmış tutulum veya serum ALP (alkalen fosfataz) seviyelerindeki artışla gösterilebilir. ${ }^{[9]}$ Osteolitik metastatik sürecin en büyük göstergesi ise kemik yıkım belirteçlerindeki artıştır. ${ }^{[9]}$ Artmış kemik rezorpsiyonu, osteoblastik karakterli metastazlarda bile başarılı tutulumun göstergesidir (Şekil 2). ${ }^{[10]}$ Prostat kanserinin

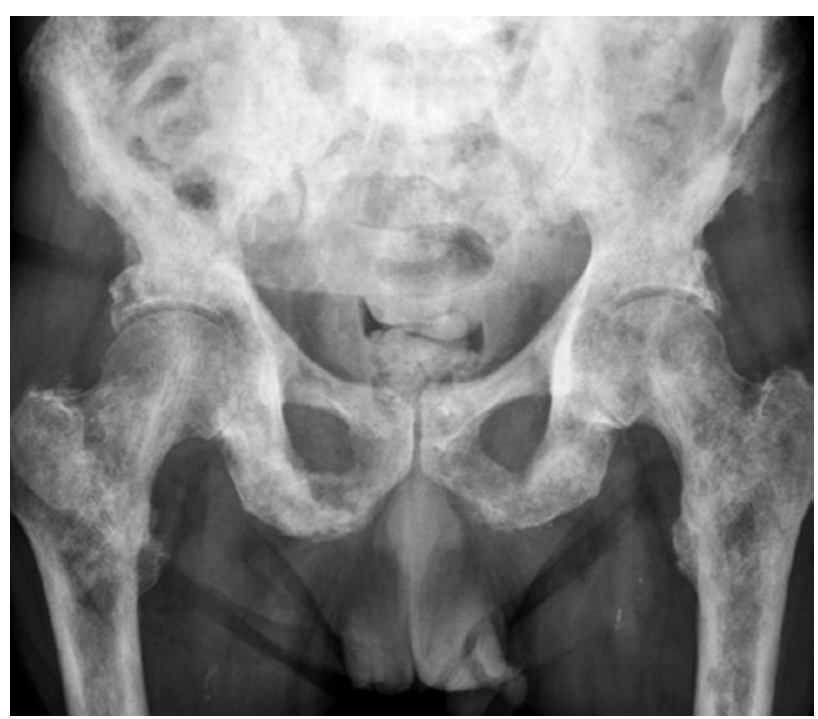

Şekil 1. Prostat kanserinde yaygın sklerotik kemik metastazları.

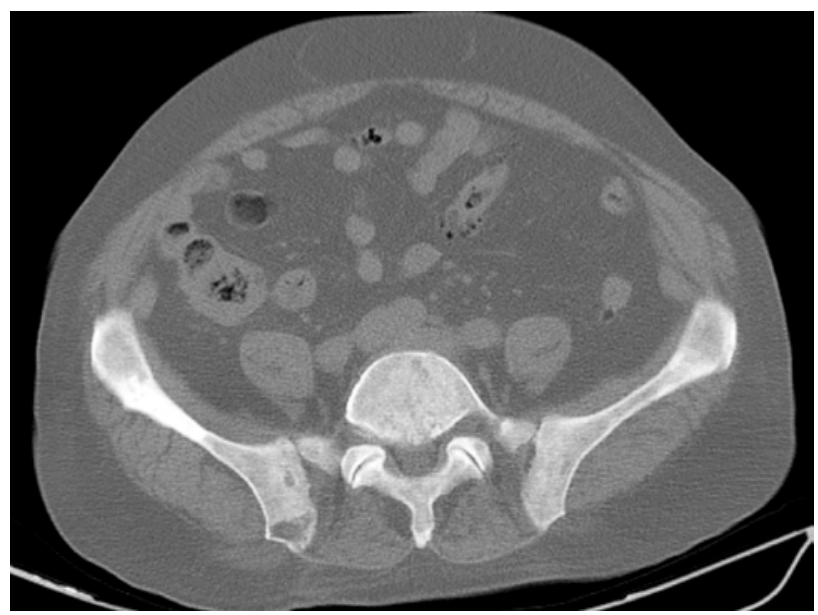

Şekil 2. Prostat kanseri metastazında pelviste her iki iliak kanatta sklerotik metastazların yanında sağ ilium posteriordaki hipodens alan.

laboratuvar modellerinde, osteoklast inhibisyonunun kemik metastazlarına karşı koruyucu olabileceği gösterilmiştir. ${ }^{[11]}$ Artmış osteoblastik aktiviteye bağlı örgülü kemik yapıda düşük kaliteli kemik yapımı ve osteoliz, metastazlarda patolojik kırık nedenlerini oluşturur. ${ }^{[12]}$

\section{KLINIK}

Günümüzde alt üriner sistem semptomları (AÜSS) olarak adlandırılan prostatizm belirtileri, prostat kanserinin başlıca semptomları arasında sayılabilir. Bu semptomlar üç başlıkta değerlendirilmektedir. ${ }^{[13]}$ 
a. Dolum fazına ait semptomlar (artmış gündüz işeme sıklığı, gece idrara sık kalkma, sıkışma, idrar kaçırma).

b. Boşaltım fazına ait semptomlar (zayıf idrar akımı, çatallı-dağınık idrar akımı, kesintili idrar akımı, gecikmeli idrar başlatma, zorlanarak idrar boşaltma, terminal damlama).

c. İşeme sonrası semptomlar (idrar boşaltımının tam olmaması duyumu, işeme sonrası damlama).

Kemik metastazları, şiddetli kemik ağrısı, patolojik kırık, medulla spinalis ve kök basıları gibi ciddi morbiditeleri de beraberinde getirir ve bu morbiditeler hastanın yaşam kalitesini önemli ölçüde düşürür. ${ }^{[14,15]}$ Daha da önemlisi, metastazlara bağlı komorbiditeler hastanın yaşam beklentisi için önemli negatif faktörlerdir. ${ }^{[15-17]}$ Metastatik prostat kanserlerinde, iskelet sistemi ile ilişkili olarak en sık patolojik kırıklar görülür. ${ }^{[18]} \mathrm{Bu}$ noktada, hasta semptomatik hale gelmeden iskelet sistemi tutulumu olup olmadığı belirlenerek periodik olarak radyolojik takiplerinin yapılması önem arz eder.

Prostat kanser metastazına bağlı kemik ağrısında nöropatik, inflamatuvar ve iskemik süreçlerin rol oynaması ve metastaz görülen kemiklerin primer duyu sinirlerinin uyarılması, bu semptomu komplike hale getirmektedir. Bu durum, metastatik hücreler, kemik matriksi ve kemik doku içerisindeki faktörlerin birbirleriyle etkileşmesi sonucu meydana gelir. ${ }^{[19]}$ Ağrıyı oluşturan nedenlerin kanser hücreleri, kemik doku ve duyu sinirlerinden kaynaklanması tedavi yönetimini zorlaştırır. ${ }^{[20]}$ Tümör kaynaklı endotelin-1 (ET-1) duyu sinir sonlanmalarındaki endotelin reseptörlerini uyararak ağrıya neden olur. Ağrıya neden olan diğer reseptörler arasında, TrK-A (tropomyosin receptor kinase-A), Trpv1 (transient receptor potential cation channel subfamily $V$ member 1) ve CGRP (calcitonin gene-related peptide) bulunmaktadır. ET-1 ve TrK-A reseptör blokajı, kemik metastazı yapmış prostat kanserli hastalarda ağrı tedavisi için başarılı bulunmuştur. ${ }^{[21]}$

\section{Radyolojik Görünüm}

Hastaların klinik şüphe dâhilinde kas-iskelet sistemi ağrıları dolayısıyla çekilen direkt grafilerinde, sıklıkla osteoblastik aktivite artışına bağlı yaygın sklerotik odaklar saptanır. Aynı şekilde, grafilerde litik lezyonlara da rastlanabilir.

MR görüntüleme için başlıca endikasyon ise, klinik şüphe sonrası US eşliğinde alınan biyopsi ile kesin tanısı konan hastalarda, evreleme için ekstrakapsüler tutulumu değerlendirmektir. Kuvvetli şüphe varlığında, eğer ki US eşliğinde alınan biyopsi sonucu negatif ise, MR eşliğinde biyopsi de alınabilir. ${ }^{[22]}$

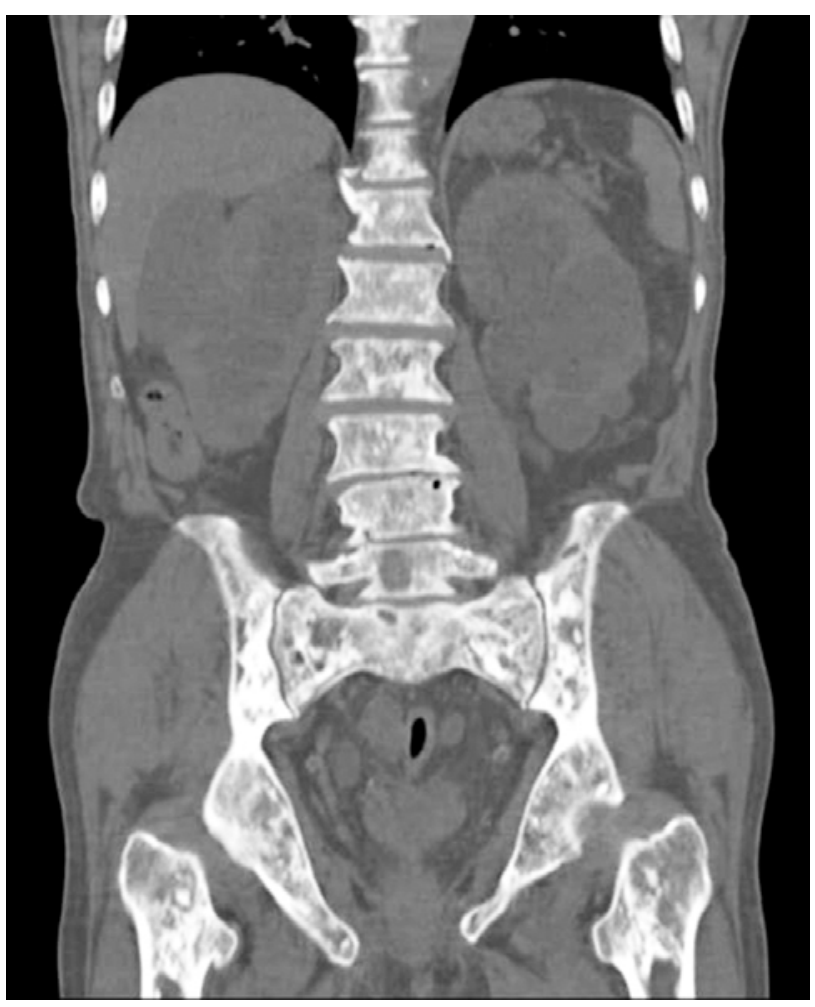

Şekil 3. Prostat kanserli bir hastada vertebralarda, pelviste her iki iliak kanatta sklerotik metastazlar ve bilateral proksimal femurda yaygın multipl osteoblastik metastatik lezyonlar.

Primer prostat kanseri tanısında yeri olmasa da, BT özellikle pelvik veya retroperitoneal masif lenf nodlarının görüntülenmesinde ve hidronefroz ve osteoblastik metastazların tanısında kullanılabilir (Şekil 3). ${ }^{[23]}$

\section{EVRELEME VE TEDAVi}

Prostat kanseri evrelemesinde klasik olarak TNM sınıflaması kullanılmaktadır. TNM evreleme sisteminde; T, kanserin organ içindeki durumunu (PSA, rektal tuşe, transrektal US ve MR ile); $N$, lenf nodu tutulumunu (BT, MR) ve $M$ ise uzak metastazını (torakoabdominal BT ve kemik sintigrafisi) belirtir. Prostat kanserinde klinik evrelemenin amacl, hastalığın yaygınlığını kestirmek ve hastalığın tahmini prognozuna göre en uygun tedavi algoritmasını oluşturmaktır. Prostat kanserinde evreleme amaciyla uygulanacak ileri tetkikler D'Amico risk sınıflamasına göre belirlenir. ${ }^{[24]}$ Buna göre, düşük riskli gruplarda evreleme amaçlı ileri radyolojik tetkik yapılması önerilmez. Gleason histolojik skoru 4'ün üzerinde olan orta risk grubundaki hastalarda ve yüksek risk grubu 


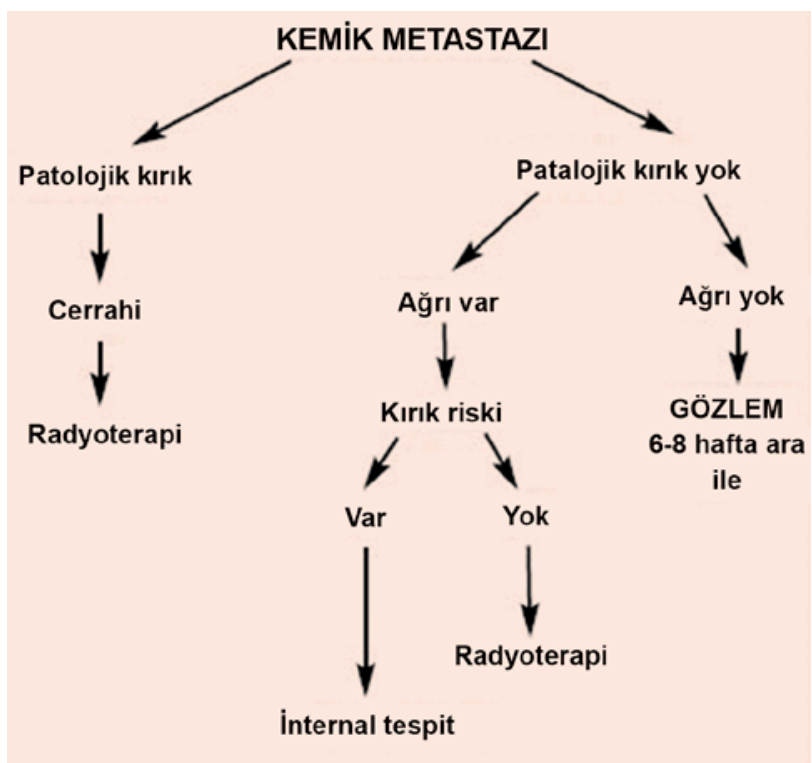

Şekil 4. Metastatik kemik tümörlerine yaklaşım algoritması.

hastalarda ise; kemik sintigrafisi, BT veya MR inceleme yapılması önerilir. Tanı alan hastalarda risk gruplarına göre uygulanabilecek tedavi yöntemleri; aktif izlem, semptomatik tedavi, radikal prostatektomi, radyoterapi ve brakiterapidir.

\section{Kemik Metaztazlı Prostat Kanserlerinde Tedavi}

Prostat kanseri kemik metastazı tedavi algoritmasında, diğer metastatik kemik tümörlerine göre önemli fark yoktur (Şekil 4). Tedavinin beş ana amacı vardır:

1) Ağrı semptomunu azaltmak.

2) Patolojik kırık gelişmesini önlemek (Şekil 5).

3) Hastanın fonksiyonel kapasitesini artırmak

4) Yaşam kalitesini yükseltmek.

5) Yaşam süresini uzatmak.

Kemiğe metastatik yayılımı olan prostat kanseri olgularında ortalama yaşam beklentisi 29 aydır ve bu süre patolojik kırık gelişimiyle beraber kısalır. ${ }^{[25]}$ Dolayısıyla tedavi algoritmasında patolojik kırık ve kırık risk varlığı önemli rol oynar. Patolojik kırık veya kırık riski olan semptomatik hastalarda uygulanacak küretaj ve kemik çimentosu ile desteklenen internal tespit tedavinin başlıca amacı olup, risk grubunda fakat asemptomatik hastalarda radyoterapi ve risk taşımayan hastalarda gözlem tercih edilir. Eklem çevresi ve eklemi ilgilendiren patolojik kırıklarda ise, tedavi seçenekleri arasında primer veya revizyon artroplasti önemli rol oynar.

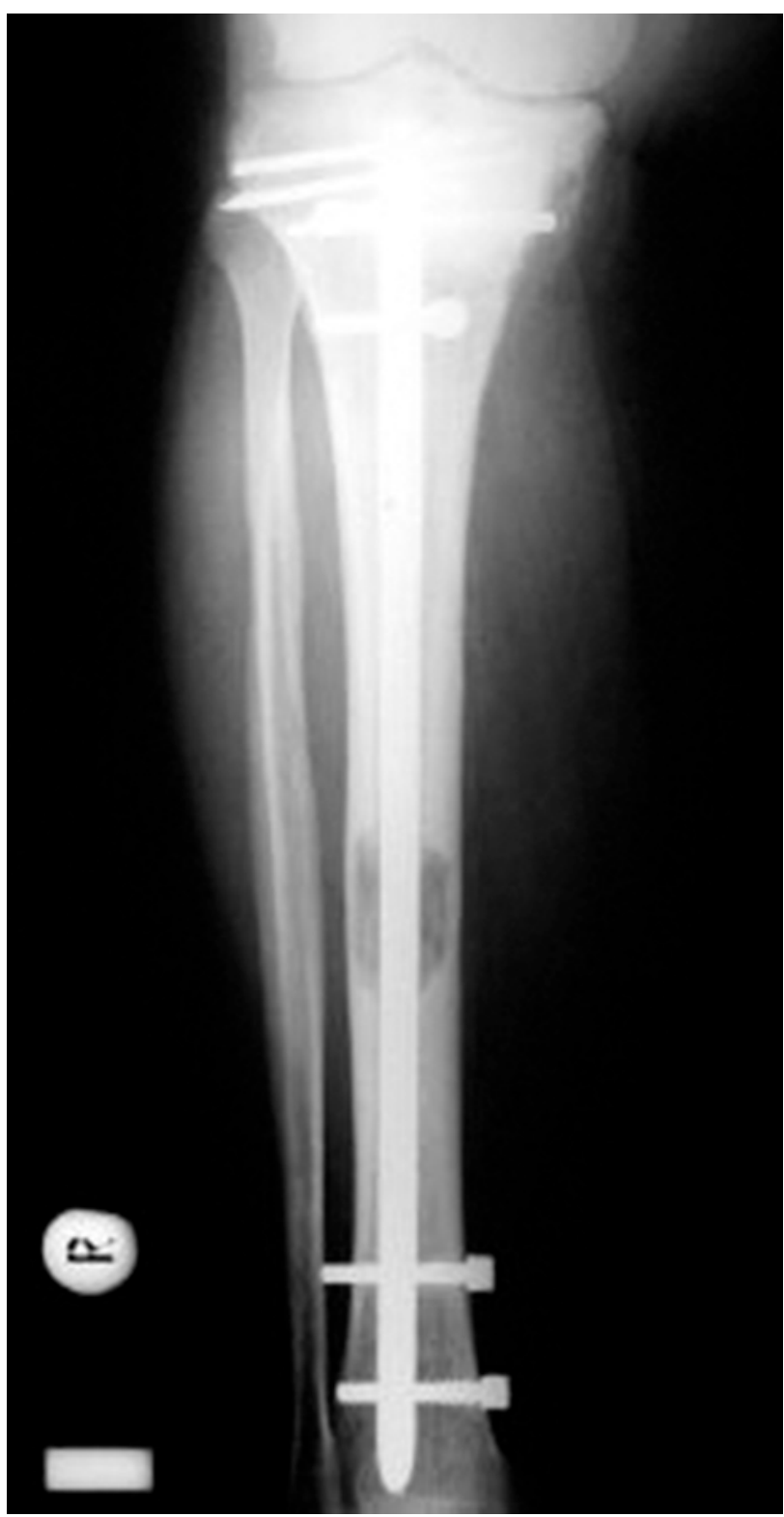

Şekil 5. Kırık gelişmeden önce kilitli intramedüller çivi ile tedavi edilmiş, tibiada prostat kanseri litik metastazı.

Gerek öncelikli olarak yassı kemik metastazı yapması gerekse kemik metastazlarının osteoblastik nitelik taşımasıyla, tedavi algoritmasında prostat kanserleri diğer tümör metastazlarından bir nebze ayrılmaktadır.

Hastalar ilk tanıda metastatik olabilecekleri gibi, birincil tedavi sonrası izlemde de metastatik hale gelebilirler. Genel durumu ve komorbiditeleri nedeniyle kemoterapi alamayacak hastalarda, tek başına hormonoterapiye (HT) başlanmalıdır. Hormonla tedavi 
sürekli veya aralıklı olarak uygulanabilir. Aralıklı tedavide, hastada PSA $<4 \mathrm{ng} / \mathrm{mL}$ olduğunda tedavi kesilir ve PSA > $20 \mathrm{ng} / \mathrm{mL}$ olduğunda tedaviye tekrar başlanmalıdır. Hormonal tedavi; cerrahi (bilateral orşiektomi) veya medikal (Luteinizan Hormon Serbestleyici Hormon [LHRH] agonistleri/antagonistleri) olarak yapılabilir. Antiandrojenlerin tek başına kullanımları artık önerilmemektedir.

Metastatik prostat kanserlerinde kullanılması tercih edilen kemik koruyucu ajanlar ise zoledronik asit (bisfosfonat) ve denosumab (RANKL [reseptör aktivatör nükleer kappa B ligand] monoklonal antikoru) olup, bu tedaviler kemoterapiye dirençli prostat kanseri hastalarında kemik metastazlarına bağlı morbiditeyi azaltmak için uygulanmalıdır.

\section{KAYNAKLAR}

1. FerlayJ, Soerjomataram I, Dikshit R, Eser S, Mathers C, Rebelo M, Parkin DM, Forman D, Bray F. Cancer incidence and mortality worldwide: Sources, methods and major patterns in GLOBOCAN 2012. Int J Cancer 2015;136(5):E359-86. Crossref

2. Schroder FH, Hugosson J, Roobol MJ, Tammela TL, Ciatto S, Nelen V, Kwiatkowski M, Lujan M, Lilja H, Zappa M, Denis LJ, Recker F, Berenguer A, Määttänen L, Bangma CH, Aus G, Villers A, Rebillard X, van der Kwast T, Blijenberg BG, Moss SM, de Koning HJ, Auvinen A; ERSPC Investigators. Screening and prostate-cancer mortality in a randomized European study. N Engl J Med 2009;360(13):1320-8. Crossref

3. Horwich A, Parker C, de Reijke T, Kataja V, on behalf of the ESMO Guidelines Working Group. Prostate cancer: ESMO Clinical Practice Guidelines for diagnosis, treatment and follow-up. Ann Oncol 2013;24 Suppl 6:vi106-14. Crossref

4. Bonekamp D, Jacobs MA, El-Khouli R, Stoianovici D, Macura $\mathrm{KJ}$. Advancements in MR imaging of the prostate: from diagnosis to interventions. Radiographics 2011;31(3):677703. Crossref

5. Scher HI, Chung LWK. Bone Metastases - Improving the Therapeutic Index. Semin Oncol 1994;21(5):630-56.

6. Gomella LG. Contemporary use of hormonal therapy in prostate cancer: managing complications and addressing quality-of-life issues. BJU Int 2007;99 Suppl 1:25-9; discussion 30. Crossref

7. Bubendorf L, Schopfer A, Wagner U, Sauter G, Moch H, Willi N, Gasser TC, Mihatsch MJ. Metastatic patterns of prostate cancer: An autopsy study of 1,589 patients. Hum Pathol 2000;31(5):578-83. Crossref

8. Wang CY, Wu GY, Shen MJ, Cui KW, Shen Y. Comparison of distribution characteristics of metastatic bone lesions between breast and prostate carcinomas. Oncol Lett 2013;5(1):391-7. Crossref

9. Coleman R, Body JJ, Aapro M, Hadji P, Herrstedt J, on behalf of the ESMO Guidelines Working Group. Bone health in cancer patients: ESMO Clinical Practice Guidelines. Ann Oncol 2014;25(Suppl 3):iii124-37. Crossref

10. Yonou H, Ochiai A, Goya M, Kanomata N, Hokama S, Morozumi M, Sugaya K, Hatano T, Ogawa Y. Intraosseous growth of human prostate cancer in implanted adult human bone: Relationship of prostate cancer cells to osteoclasts in osteoblastic metastatic lesions. Prostate 2004;58(4):406-13. Crossref
11. Guise TA, Mohammad KS, Clines G, Stebbins EG, Wong $\mathrm{DH}$, Higgins LS, Vessella R, Corey E, Padalecki S, Suva L, Chirgwin JM. Basic mechanisms responsible for osteolytic and osteoblastic bone metastases. Clin Cancer Res 2006;12(20):6213s-6s. Crossref

12. Keller ET, Brown J. Prostate cancer bone metastases promote both osteolytic and osteoblastic activity. J Cell Biochem 2004;91(4):718-29. Crossref

13. Abrams $P$, Cardozo L, Fall M, Griffiths $D$, Rosier $P$, Ulmsten $U$, Van Kerrebroeck P, Victor A, Wein A; Standardisation Sub-Committee of the International Continence Society. The standardisation of terminology of lower urinary tract function: report from the Standardisation Sub-committee of the International Continence Society. Urology 2003;61(1):3749. Crossref

14. Weinfurt KP, Li Y, Castel LD, Saad F, Timbie JW, Glendenning GA, Schulman KA. The significance of skeletal-related events for the health-related quality of life of patients with metastatic prostate cancer. Ann Oncol 2005;16(4):579-84. Crossref

15. Park SH, Eber MR, Shiozawa Y. Models of Prostate Cancer Bone Metastasis. Methods Mol Biol 2019;1914:295-308. Crossref

16. Sabbatini $P$, Larson $S M$, Kremer $A$, Zhang ZF, Sun M, Yeung $\mathrm{H}$, Imbriaco M, Horak I, Conolly M, Ding C, Ouyang P, Kelly WK, Scher HI. Prognostic significance of extent of disease in bone in patients with androgen-independent prostate cancer. J Clin Oncol 1999;17(3):948-57. Crossref

17. Halabi S, Vogelzang NJ, Kornblith AB, Ou SS, Kantoff PW, Dawson NA, Small EJ. Pain predicts overall survival in men with metastatic castration-refractory prostate cancer. J Clin Oncol 2008;26(15):2544-9. Crossref

18. Saad F, Gleason DM, Murray R, Tchekmedyian S, Venner P, Lacombe L, Chin JL, Vinholes JJ, Goas JA, Chen B; Zoledronic Acid Prostate Cancer Study Group. A randomized, placebocontrolled trial of zoledronic acid in patients with hormonerefractory metastatic prostate carcinoma. J Natl Cancer Inst 2002;94(19):1458-68. Crossref

19. Muralidharan A, Smith MT. Pathobiology and management of prostate cancer-induced bone pain: recent insights and future treatments. Inflammopharmacology 2013;21(5):33963. Crossref

20. Falk S, Dickenson AH. Pain and Nociception: Mechanisms of Cancer-Induced Bone Pain. J Clin Oncol 2014;32(16):164754. Crossref

21. Clines GA, Guise TA. Molecular mechanisms and treatment of bone metastasis. Expert Rev Mol Med 2008;10:e7. Crossref

22. Roethke M, Anastasiadis AG, Lichy M, Werner M, Wagner P, Kruck S, Claussen CD, Stenzl A, Schlemmer HP, Schilling D. MRI-guided prostate biopsy detects clinically significant cancer: analysis of a cohort of 100 patients after previous negative TRUS biopsy. World J Urol 2012;30(2):213-8. Crossref

23. Prando A, Wallace S. Helical CT of prostate cancer: early clinical experience. AJR Am J Roentgenol 2000;175(2):343-6. Crossref

24. D'Amico AV, Whittington R, Malkowicz SB, Schultz D, Blank K, Broderick GA, Tomaszewski JE, Renshaw AA, Kaplan I, Beard CJ, Wein A. Biochemical outcome after radical prostatectomy, external beam radiation therapy, or interstitial radiation therapy for clinically localized prostate cancer. JAMA 1998;280(11):969-74. Crossref

25. Hipp JA, Springfield DS, Hayes WC. Predicting pathologic fracture risk in the management of metastatic bone defects. Clin Orthop Relat Res 1995;(312):120-35. 